\title{
OPERATIONAL SAR DATA PROCESSING IN GIS ENVIRONMENTS FOR RAPID DISASTER MAPPING
}

\author{
A. Meroni ${ }^{\text {a }}$ T. Bahr ${ }^{\mathrm{b}}$
}

${ }^{a}$ Exelis Visual Information Solutions, Concorezzo, Italy - alberto.meroni@exelisvis.com

${ }^{\mathrm{b}}$ Exelis Visual Information Solutions GmbH, Gilching, Germany - thomas.bahr@exelisvis.com

KEY WORDS: Public Safety, Disaster Mapping, Change Detection, SAR, Model, COSMO-SkyMed, SARscape, ArcGIS ${ }^{\circledR}$, IDL

\begin{abstract}
:
Having access to SAR data can be highly important and critical especially for disaster mapping. Updating a GIS with contemporary information from SAR data allows to deliver a reliable set of geospatial information to advance civilian operations, e.g. search and rescue missions. Therefore, we present in this paper the operational processing of SAR data within a GIS environment for rapid disaster mapping. This is exemplified by the November 2010 flash flood in the Veneto region, Italy. A series of COSMO-SkyMed acquisitions was processed in ArcGIS ${ }^{\circledR}$ using a single-sensor, multi-mode, multi-temporal approach. The relevant processing steps were combined using the ArcGIS ModelBuilder to create a new model for rapid disaster mapping in ArcGIS, which can be accessed both via a desktop and a server environment.
\end{abstract}

\section{INTRODUCTION}

The use of SAR data has become increasingly popular in recent years and in a wide array of industries. Having access to SAR data can be highly important and critical especially for disaster management. SAR imaging offers the great advantage, over its optical counterparts, of not being affected by darkness, meteorological conditions such as clouds, fog, etc., or smoke and dust, frequently associated with disaster zones.

Updating a GIS with contemporary information from SAR data allows to deliver a reliable set of geospatial information to advance civilian operations, e.g. search and rescue missions.

To solve this requirement, we developed an operational processing chain for SAR data within a GIS environment, which can be executed by the responsible operators without SAR expert knowledge.

For this approach we integrated the SARscape modules for ENVI with ArcGIS ${ }^{\circledR}$, eliminating the need to switch between software packages. Thereby the premier algorithms for SAR image analysis can be directly accessed from ArcGIS desktop and server environments. They allow processing and analyzing SAR data in almost real time and with minimum user interaction. Thus disaster zones, e.g. after severe flooding, can be automatically identified and mapped to support local task forces.

\section{CASE STUDY: FLOOD DETECTION WITH HIGH- RESOLUTION COSMO-SKYMED DATA}

The Bacchiglione River burst its banks on Nov. $2^{\text {nd }} 2010$ after two days of heavy rainfall throughout the northern Italian region (GMES Emergency Response Service (Ed.), 2010). The community of Bovolenta, $22 \mathrm{~km}$ SSE of Padova, was covered by several meters of water. People were requested to stay in their homes; several roads, highways sections and railroads had to be closed.
The extent of this flooding is documented by a series of COSMO-SkyMed acquisitions. COSMO-SkyMed is a constellation of four X-band Earth observation satellites, allowing a very frequent coverage, which enables monitoring using a very high temporal resolution.

For the present case study we focused on a COSMO-SkyMed-2 image acquired at Nov. $5^{\text {th }} 2010$, i.e. 3 days after the flash flood (see Figure 1). As a reference we used a COSMO-SkyMed-3 image, acquired at May $9^{\text {th }} 2010$. Both images were acquired in StripMap mode and ordered as Detected Ground Multi-look (DGM) product (Level 1B) with a GSD of $2.5 \mathrm{~m}$ and $\mathrm{HH}$ polarization.

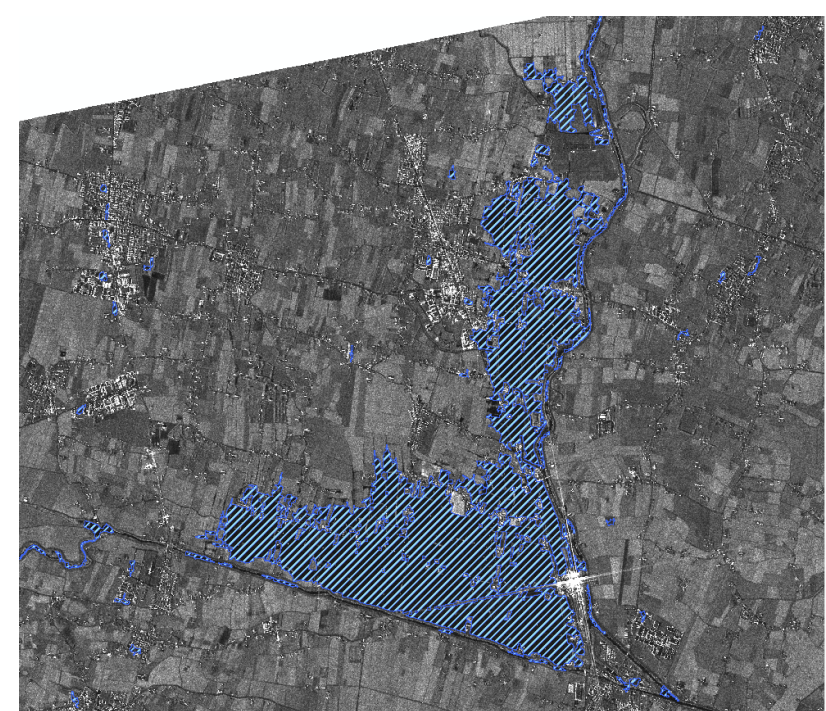

Figure 1. COSMO-SkyMed 2, StripMap DGM, Nov. $5^{\text {th }} 2010$, "Gaussian DE MAP" filtered, DEM-geocoded \& calibrated, flooded areas overlaid.

(C) COSMO-SkyMed ${ }^{\mathrm{TM}}$ Product - ASI, 2010. All rights reserved. Distributed by e-GEOS. 


\section{THE SAR DATA PROCESSING WORKFLOW}

This data is processed using a single-sensor, multi-mode, multitemporal approach consisting of 3 steps:

Step 1: The single images are filtered with a Gamma Distribution-Entropy Maximum a Posteriori (DE-MAP) filter to reduce the speckle effect. In this way, the restoration of the local textural properties of the scene does not depend on any assumption regarding the form of its statistical distribution (sarmap SA (Ed.), 2012).

Step 2: The filtered images are geocoded using a reference DEM (SRTM3v4) without the need of ground control points. Geocoding is performed by rigorously applying the Range and Doppler equations. Thus, the map locations for every pixel are precisely determined. This step includes the radiometric calibration, which is carried out by following the radar equation law (sarmap SA (Ed.), 2012).

Step 3: A subsequent change detection analysis generates the final map showing the extent of the flash flood on Nov. $5^{\text {th }} 2010$ (see Figure 1). This process is customized to the task and combines band arithmetic, segmentation, morphology filtering, and raster-to-vector conversion.

\section{IMPLEMENTATION OF THE WORRKFLOW IN ARCGIS}

These 3 processing steps are combined using the ArcGIS ModelBuilder to create a new model for rapid disaster mapping in ArcGIS, based on SAR data.

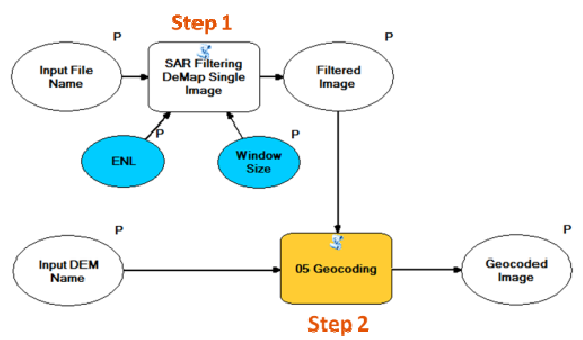

Figure 2. ArcGIS model for filtering (step 1) and geocoding (step 2) of a single COSMO-SkyMed image.

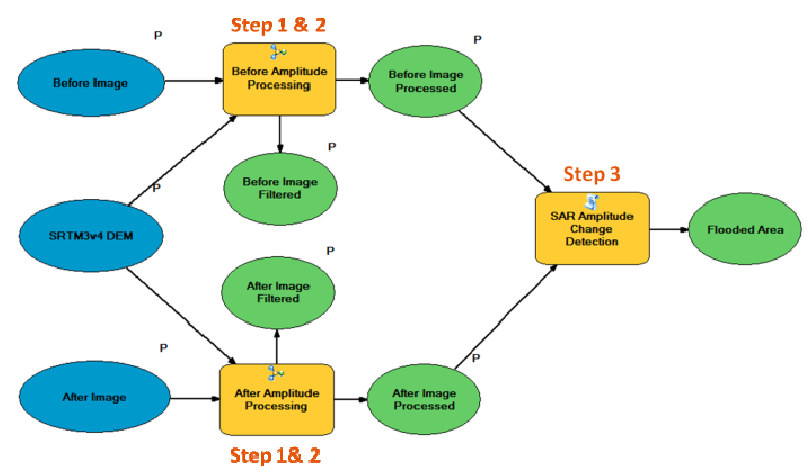

Figure 3. ArcGIS model for the complete SAR processing workflow including the final change detection analysis (step 3). "Before Image": May $9^{\text {th }}$ 2010. "After Image": Nov. $5^{\text {th }} 2010$.
Filtering (step 1) and geocoding (step 2) of a single COSMOSkyMed image are integrated in a sub-model (see Figure 2), which is called twice in the main model, both for the "before" (May $9^{\text {th }} 2010$ ) and the "after" (Nov. $5^{\text {th }} 2010$ ) image (see Figure 3). The two process sequences converge in the final change detection analysis (step 3 ).

The underlying algorithms are provided by three different sources: Geocoding \& radiometric calibration (step 2) is a standard functionality from the commercial SARscape Toolbox for ArcGIS. This toolbox is extended by the filter tool (step 1), which is called from the SARscape modules in ENVI. The change detection analysis (step 3) is based on ENVI processing routines and scripted with the interactive data language IDL.

The three tools are implemented in ArcGIS using a Python script file. This script file retrieves the parameters from the ArcGIS user interface and invokes the ENVI/IDL-based entry point procedure stored in an IDL sav file, consisting of the precompiled IDL code (Exelis Visual Information Solutions (Ed.), 2012).

\section{CONCLUSIONS}

Exemplified by the November 2010 flash flood in the Veneto region, Italy, we developed an operational workflow for change detection analysis with SAR data, provided as an additional ArcGIS toolbox. Thus disaster zones, e.g. after severe flooding, can be automatically identified and mapped to support local task forces.

The benefits of the resulting processing chain include its execution by the responsible operators without SAR expert knowledge in a familiar GIS environment. Moreover, the open architecture platform IDL allows to customize single processing steps, or to create additional tools from the full complement of ENVI functionality. These image analysis processes can be integrated into any other ArcGIS models to update a GIS with contemporary information from remotely sensed data. Finally, the ArcGIS model presented here can be dissolved from its desktop environment and published to users across the ArcGIS Server enterprise.

\section{REFERENCES}

Exelis Visual Information Solutions (Ed.), 2012. ENVI Documentation, ENVI v5.0.

GMES Emergency Response Service (Ed.), 2010. http://www.emergencyresponse.eu/gmes/en/event/Floods-inItaly_27.html, 24.01.2013.

sarmap SA (Ed.), 2012. SARscape Documentation, SARscape v4.4.003. 